\title{
Prevalence of comorbidities among patients with Acromegaly
}

\author{
Sajjad Ali Khan', Nanik Ram², \\ Muhammad Qamar Masood ${ }^{3}$, Najmul Islam ${ }^{4}$
}

\begin{abstract}
Background and Objective: Acromegaly is a chronic disorder resulting from excessive secretion of growth hormone and $(\mathrm{GH})$ and insulin-like growth factor 1 (IGF-1) and is associated with several comorbidities. These complications contribute significantly to morbidity and mortality associated with this condition thus early diagnosis leads to better outcomes. There have been studies in other countries to assess the comorbidities associated with acromegaly. However, we do not have any recent data with regards to Pakistan. So, in order to demonstrate the prevalence of demographics, hormonal disorders, and other complications associated with acromegaly we conducted this study.

Methods: It is a retrospective review of patients' records presented to the tertiary care Hospital, Karachi, Pakistan for the diagnosis and management of acromegaly and the complications associated with this condition between the time periods 2000 till 2020. A total of 89 patients fulfilled the inclusion criteria of acromegaly and were included in the study. Comorbid conditions were described based on current guidelines. Patient baseline characteristics were recorded along with other complications arising during treatment.

Results: Eighty-nine patients were included. $64 \%$ were male, over $70 \%$ were older than 30 years old and more than $40 \%$ of patients had BMI greater than 30. HTN, pre-hypertension, and CCF were reported in $35.95 \%, 3.37 \%$, and $6.74 \%$. Diabetes mellitus, hypocortisolism, hypothyroidism, hypogonadism, and hyperprolactinemia were reported in $39.32 \%, 38.20 \%, 37.07 \%, 34.46 \%$, and $16.85 \%$ of cases. The prevalence of osteoarthritis, blood disorder, skin changes, thyroid cancer, and spinal stenosis was found out to be around $1.12 \%$ each.

Conclusions: Acromegaly is associated with cardiovascular and endocrinal disorders. Screening for these disorders at the time of diagnosis can lead to early management and better outcomes translating into decreased mortality.
\end{abstract}

KEYWORDS: Acromegaly, Complications, Comorbidities.

doi: https://doi.org/10.12669/pjms.37.7.4277

How to cite this:

Khan SA, Ram N, Masood MQ, Islam N. Prevalence of comorbidities among patients with Acromegaly. Pak J Med Sci. 2021;37(7):1758-1761. doi: https://doi.org/10.12669/pjms.37.7.4277

This is an Open Access article distributed under the terms of the Creative Commons Attribution License (http://creativecommons.org/licenses/by/3.0), which permits unrestricted use, distribution, and reproduction in any medium, provided the original work is properly cited.

Dr. Sajjad Ali Khan, FCPS.

Dr. Nanik Ram, FCPS.

Dr. Muhammad Qamar Masood, MD.

4. Dr. Najmul Islam, FRCP.

1-4: Department of Medicine, Section of Endocrinology,

Aga Khan University Hospital, Karachi, Pakistan.

Correspondence:

Dr. Nanik Ram, FCPS.

Assistant Professor, Department of Medicine,

Aga Khan University Hospital,

Karachi, Pakistan.

E-mail: nanik.ram@aku.edu

* Received for Publication:

* Accepted for Publication:

February 23, 2021

June 5, 2021

\section{INTRODUCTION}

Acromegaly is a chronic progressive disease caused by an excess secretion of growth hormone from the pituitary adenomas and the resultant increase in an insulin-like growth factor (IGF-1). Chronic exposure to high levels of GH leads to a variety of complications. It has been postulated that it is associated with two to three time's higher mortality than the general population.

The mortality is related to an excess of cardiovascular (hypertension, heart failure), 
cerebrovascular (stroke), and respiratory disorders (obstructive sleep apnea). Moreover, studies have reported a higher prevalence of malignancies, osteoarthritic changes, endocrinological and metabolic disorders in the form of hyperglycemia, lipid disorders to name a few. As a result of these morbidities, the mortality rate is increased in these patients. ${ }^{1}$

It has been recommended to diagnose these disorders earlier on before they become irreversible. Among all the complications, cardiovascular disorders account for a greater than two-third of morbidities and around half of the mortality. ${ }^{2}$ Among the cardiovascular disorders, studies have reported cardiomyopathies, ischemic heart disease, systemic arterial hypertension, rhythm disorders, and valvular lesions in various frequencies. Among these cardiomyopathies, leading to heart failure and systemic hypertension are much more prevalent than others. ${ }^{3,4}$ Respiratory disorders in the form of obstructive sleep apnea and respiratory insufficiency can lead to morbidities in these patients. ${ }^{5-7}$ Among the metabolic complications, studies have reported varying frequencies of dysglycemia, impaired fasting glucose, and impaired glucose tolerance. ${ }^{8,9}$

Our objective was to demonstrate the prevalence of demographics, hormonal disorders, and other complications associated with acromegaly

\section{METHODS}

It was a retrospective review of patients' records presented to the tertiary care Hospital, Karachi, Pakistan for the diagnosis and management of acromegaly. After the approval from the ethical review committee (ERC) of our center, we requested the health information and management services (HIMS) to provide the list of patients diagnosed to have pituitary tumors.

A total of 89 patients fulfilled the diagnosis of acromegaly based on the clinical characteristics and biochemical markers and were included in the study. These patients were either undergoing treatment with surgery/ medical therapy for acromegaly or on being followed up in a tertiary care hospital, Karachi, Pakistan.

The inclusion criteria included confirmed cases of acromegaly fulfilling the clinical features and endocrine society diagnostic criteria, i.e. 1) patients with elevated or equivocal serum IGF-1 levels matched for age and sex, and confirmation of the diagnosis by finding lack of suppression of GH to $<1 \mu \mathrm{g} / \mathrm{L}$ following documented hyperglycemia during an oral glucose load. ${ }^{10}$
Patients aged 15 years or below were also excluded from the study, as body mass index (BMI) and blood pressure vary in childhood. Data was collected retrospectively by reviewing the patient records for both the baseline and subsequent visit post-intervention (surgery and medical therapy).

For each patient, we analyzed the following data recorded by the primary physician at the diagnosis of acromegaly: age and sex, BMI, estimated duration since acromegaly diagnosis, mean serum GH, IGF-1 level (matched for age and sex in each center), pituitary tumor size measured by magnetic resonance imaging (MRI), and presence of, FBS, two hours glucose level (RBS) and $\mathrm{HbA1C}$. Endocrine Society guidelines were used to report hypothyroidism, hypogonadism, adrenal insufficiency, and hyperprolactinemia. ${ }^{11}$

We reviewed the patient records and the echocardiographic findings for the diagnosis of cardiomyopathy and valvular lesions. Similarly, musculoskeletal disorders were recorded as mentioned in the records based on the radiological investigation done during the treatment of acromegaly. With regards to dysglycemia, patients were classified according to the diagnostic criteria of the American Diabetes Association (ADA). ${ }^{12}$

Blood pressure was classified according to the recently released Seventh Report of the Joint National Committee (JNC) on Prevention, Detection, Evaluation, and Treatment of High Blood Pressure. A systolic B.P (SBP) of 120 to $139 \mathrm{~mm} \mathrm{Hg}$ or a DBP of 80 to $89 \mathrm{~mm} \mathrm{Hg}$ is defined as prehypertension. Hypertension is classified using cutoff points of SBP of $140 \mathrm{~mm} \mathrm{Hg}$ or higher or DBP of $90 \mathrm{~mm}$ $\mathrm{Hg}$ or higher. ${ }^{13}$ Patient data was then entered in excel initially and then all statistical analyses were performed using the SPSS 16.0 software.

Table-I: General characteristics of patients.

\begin{tabular}{llc}
\hline & & $N(\%)$ \\
\hline \multirow{3}{*}{ Age } & 15-30 years & $26(29.21)$ \\
& 30-45 years & $43(48.31)$ \\
& $>45$ years & $20(22.47)$ \\
Gender & Male & $57(64.0)$ \\
& Female & $32(35.95)$ \\
& $<25$ & $12(13.43)$ \\
BMI & $25-30$ & $33(37.07)$ \\
& $30-35$ & $36(40.44)$ \\
& $>35$ & $8(8.98)$ \\
\hline
\end{tabular}

BMI, body mass index; $\mathrm{cm}$, centimetre;

$>$, greater than; <, less than; \%, Percentage. 


\section{RESULTS}

The general characteristics of the study population are shown in Table-I. The majority of the study patients were young falling in the age range between 15 to 45 years of age $(77.54 \%)$ with sixtyfour percent being males. Most of the patients had a BMI between 25-35 (77.51\%) and were diagnosed within five years of disease onset $(67.41 \%)$.

The prevalence of cardiovascular, respiratory, musculoskeletal, skin and blood disorders is shown in Table-II. The table shows that $3.37 \%$ ( $n=$ 3 ) of the patients were in a state of pre-hypertension and $35.95 \%(n=32)$ of the patients were reported to be hypertensive. $6.74 \%(\mathrm{n}=6)$ of the patients had comorbid CCF, OSA was reported in a subset of patients $14.8 \%(n=12)$.

The frequency of various endocrine disorders in our study population areillustrated in Table-III. Our study reviewed multiple hormonal abnormalities that coexisted in patients with pituitary adenoma, including hypothyroidism, hypocortisolism, hypogonadism, and prolactinoma.

\section{DISCUSSION}

For this study, we assessed 89 Patients that is after applying exclusion criteria. Males accounted

Table-II: Frequency of cardiovascular, respiratory, and other conditions.

\begin{tabular}{lc}
\hline Disorder & $N(\%)$ \\
\hline Pre-Hypertension & $3(3.37)$ \\
Hypertension & $32(35.95)$ \\
Congestive Cardiac Failure & $6(6.74)$ \\
Infective Endocarditis & $1(1.12)$ \\
Cardiac Valvular Lesions & $2(2.24)$ \\
Obstructive sleep apnea & $12(14.8 \%)$ \\
Osteoarthritis & $1(1.12)$ \\
Osteoporosis & $2(2.24)$ \\
Spinal Stenosis & $1(1.12)$ \\
Multinodular Goiter & $2(2.24)$ \\
Thyroid Nodule & $1(1.12)$ \\
Thyroid Cancer & $1(1.12)$ \\
Colonic Polyp & $2(2.24)$ \\
Skin Tags \& Gastrointestinal & $1(1.12)$ \\
Bleeding \& Myopathy & $1(1.12)$ \\
Deafness & $1(1.12)$ \\
Blood Disorder & $4(4.49)$ \\
\hline Peripheral Neuropathy & \\
\hline
\end{tabular}

for a higher proportion of our study population $(64.0 \%)$. Our study found that the highest incidence of pituitary adenoma with acromegaly occurred in the middle age group $30-45$-year-old $(40.44 \%)$, and most people had above-normal BMI >25-30.

Our study shows a very high prevalence of diabetes $39.32 \%$ among acromegalic patients as compared to the general population of this country $19.4 \%$ as shown in the International Diabetes Federation Diabetes Atlas, $9^{\text {th }}$ edition. ${ }^{14}$ Furthermore, the prevalence of prediabetes (IFG, IGT) was $12.35 \%$ among acromegalic patients.

This higher prevalence of $39.32 \%$ is in parallel withover $50 \%$ of prevalence reported in the Russian population reported by A V Deval et al, ${ }^{8}$ $31.9 \%$ in the Mexican population, ${ }^{15} 28 \%$ in the Belgian population. Cardiovascular complications are very common in acromegaly. The Prevalence of pre-hypertension and hypertension in our study was found to be $3.37 \%$ and $35.95 \%$ respectively which is comparable to other studies done in other countries. ${ }^{16,17}$ However, it was much higher $(26.34 \%$ vs $35.95 \%)$ than the general population as reported in a recent metanalysis. ${ }^{18}$ Our study reports the frequency of Congestive Cardiac Failure as a comorbid condition to be $6.67 \%$, whereas in literature it is reported to be ranging between 1 and $4 \% .^{19}$

Similarly, our study reveals that the prevalence of valvular lesions and infective endocarditis is 2.24 and $1.12 \%$ respectively. This is inconsistent with studies reported earlier. ${ }^{20}$ The prevalence of OSA in our study was reported to be $12(14.8 \%)$ in contrast

Table-III: Endocrine related disorders in acromegaly.

\begin{tabular}{lc}
\hline Disorder & $N(\%)$ \\
\hline Normoglycemics & $43(48.3 \%)$ \\
Diabetes Mellitus & $35(39.32)$ \\
Impaired Fasting Glucose & $5(5.61)$ \\
Impaired Fasting Glucose \& & $5(5.61)$ \\
Impaired Glucose Tolerance & $34(38.20)$ \\
Hypocortisolism & $28(31.46)$ \\
Hypogonadism & $15(16.85)$ \\
Prolactinoma & $33(37.07)$ \\
Hypothyroidism & $10(12.3)$ \\
Dyslipidemia & $15(16.85)$ \\
Prolactinoma & $10(31.25)$ \\
Amenorrhea & $6(10.52)$ \\
Impotence & $4(4.49)$ \\
Infertility &
\end{tabular}


other studies report a much higher prevalence of OSA ranging from $27 \%$ in older studies to over $80 \%$ in other studies. ${ }^{21}$ As it is linked to higher BMI, and generally underreported. Hypopituitarism is a known complication of acromegaly leading to secondary adrenal insufficiency, hypogonadotropic hypogonadism, and secondary hypothyroidism. In our dataset, Hormonal abnormalities were reported to be $38.20 \%, 31.46 \%, 37.07 \%$ for hypocortisolism, hypogonadism, and hypothyroidism respectively. The prevalence of hyperprolactinemia was found out to be $16.85 \%$ which is lower than the previously reported $(30 \%) .{ }^{22}$ Similarly, the prevalence of amenorrhea and infertility was found in $11.23 \%$ and $4.49 \%$ respectively which is much lower than other studies. ${ }^{23}$ One of the possible reasons could be the fewer number of female patients in our cohort.

Our study reports that the prevalence of osteoarthritis and spinal stenosis is $2.24 \%, 1.12 \%$, and $1.12 \%$ respectively. This is in contrast to other studies that reported a very high prevalence of arthropathy of $56 \%,{ }^{24}$ and $10.6 \%$ for vertebral fractures. ${ }^{25}$ Most of our patients presented earlier (< 5 years), this might be the reason for the low rates of rheumatological disorders. Studies have reported a higher prevalence of GI cancers in acromegalic patients. In contrast, our study did not find any significant association between acromegaly colon cancers. Only $2.24 \%$ of patients had colonic polyps which is much lower than reported in other studies.

\section{CONCLUSION}

Acromegaly is associated with several comorbid conditions most importantly cardiovascular and metabolic complications. Early diagnosis can lead to a better outcome.

\section{Grant Support E Financial Disclosures: None.}

\section{REFERENCES}

1. Gadelha MR, Kasuki L, Lim DS Fleseriu M. Systemic complications of acromegaly and the impact of the current treatment landscape: an update. Endocr Rev. 2019;40:268-332.

2. Holdaway IM, Rajasoorya RC \& Gamble GD. Factors influencing mortality in acromegaly. J Clin Endocrinol Metab. 2004;89:667-674

3. Colao A, Ferone D, Marzullo P Lombardi G. Systemic complications of acromegaly: epidemiology, pathogenesis, and management. Endocr Rev. 2004;25:102-152.

4. Kahaly G, Olshausen KV, Mohr-Kahaly S, Erbel R, Boor S, Beyer J \& Meyer J. Arrhythmia profile in acromegaly. Eur Heart J. 1992;13:51-56.

5. Alexander L, Appleton D, Hall R, Ross WM Wilkinson R. Epidemiology of acromegaly in the Newcastle region. Clin Endocrinol (Oxf) 1980;12:71-79.

6. Turan O, Akinci B, Ikiz AO, Itil O, Oztura I, Ada E, et al. Airway and sleep disorders in patients with acromegaly. Clin Respir J. 2018;12:1003-1010.
7. Zhang F, Guo X, Gao L, Wang Z, Feng C, Jia M, et al. Lung function and blood gas abnormalities in patients with acromegaly. J Clin Neurosci. 2020;73:130-135.

8. Dreval AV, Trigolosova IV, Misnikova IV, Kovalyova YA, Tishenina RS, Barsukov I, et al. Prevalence of diabetes mellitus in patients with acromegaly. Endocrine Connections. 2014;3:93-98.

9. Basit A, Fawwad A, Qureshi H, Shera A. Prevalence of diabetes, pre-diabetes and associated risk factors: second National Diabetes Survey of Pakistan (NDSP), 2016-2017. BMJ open 2018;8:e20961.

10. Katznelson L, Laws Jr ER, Melmed S, Molitch ME, Murad MH, Utz A, et al. Acromegaly: an endocrine society clinical practice guideline. J Clin Endocrinol Metabol. 2014;99:3933-3951.

11. Fleseriu M, Hashim IA, Karavitaki N, Melmed S, Murad MH, Salvatori $\mathrm{R}$, et al. Hormonal replacement in hypopituitarism in adults: an endocrine society clinical practice guideline. The J Clin Endocrinol Metabol. 2016;101:3888-3921.

12. Association AD. 2. Classification \& diagnosis of diabetes: Standards of Medical Care in Diabetes-2020. Diabet Care. 2020;43:S14-S31.

13. Wang Y, Wang QJ. The Prevalence of Prehypertension and Hypertension Among US Adults According to the New Joint National Committee Guidelines: New Challenges of the Old Problem. Arch Int Med: 2004;164:2126-2134.

14. Saeedi P, Petersohn I, Salpea P, Malanda B, Karuranga S, Unwin $\mathrm{N}$, et al. Global and regional diabetes prevalence estimates for 2019 and projections for 2030 and 2045: Results from the International Diabetes Federation Diabetes Atlas. Diabet Res Clin Pract. 2019;157:107843.

15. Espinosa-de-los-Monteros AL, Gonzalez B, Vargas G, Sosa E \& Mercado M. Clinical and biochemical characteristics of acromegalic patients with different abnormalities in glucose metabolism. Pituitary 2011;14:231-235.

16. Bondanelli M, Ambrosio MR \& degli Uberti EC. Pathogenesis \& prevalence of hypertension in acromegaly. Pituitary. 2001;4:239-249.

17. Puglisi S \& Terzolo M. Hypertension and Acromegaly. Endocrinol Metab Clin North Am. 2019;48:779-793.

18. Shah N, Shah Q \& Shah AJ. The burden and high prevalence of hypertension in Pakistani adolescents: a meta-analysis of the published studies. Arch Pub Health. 2018;76:20.

19. Colao A, Grasso LFS, Di Somma C, Pivonello R. Acromegaly and Heart Failure. Heart Fail Clin. 2019;15:399-408.

20. Ohtsuka G, Aomi S, Koyanagi H, Tsukui H, Tomizawa Y, Hashimoto A, et al. Heart valve operation in acromegaly. Ann Thorac Surg.1997;64:390-393

21. van Haute FR, Taboada GF, Corrêa LL, Lima GA, Fontes R, Riello $\mathrm{AP}$, et al. Prevalence of sleep apnea and metabolic abnormalities in patients with acromegaly and analysis of cephalometric parameters by magnetic resonance imaging. Eur J Endocrinol. 2008;158:459-465.

22. Lugo G, Pena L, Cordido F. Clinical manifestations and diagnosis of acromegaly. Int J Endocrinol. 2012;2012:540398.

23. Katznelson L, Kleinberg D, Vance ML, Stravou S, Pulaski KJ, Schoenfeld DA, et al. Hypogonadism in patients with acromegaly: data from the multi-centre acromegaly registry pilot study. Clin Endocrinol. 2001;54:183-188.

24. Kropf LL, Madeira M, Vieira Neto L, Gadelha MR, de Farias ML. Functional evaluation of the joints in acromegalic patients and associated factors. Clin Rheumatol. 2013;32:991-998.

25. Madeira M, Neto LV, Torres CH, de Mendonça LM, Gadelha MR \& de Farias ML. Vertebral fracture assessment in acromegaly. J Clin Densitom. 2013;16:238-243.

\section{Authors' Contribution:}

NA: Conceived, designed, and did statistical analysis.

SAK: Did data collection and manuscript writing.

MQM: Did the editing of the manuscript.

NI: Did a review and final approval of the manuscript. 